\title{
Effect of manual therapy on pain and electromyographic activity of masticatory muscles in patients with temporomandibular disorders
}

\author{
Priscila Bageston de Britto', Maurício André Bisi', William Dhein
}

\begin{abstract}
Background: Temporomandibular disorders (TMD) are disorders of multifactorial origin that affect the temporomandibular joint and/or masticatory muscles. The TMD can generate compensations where physical therapy acts through myofascial releases and joint mobilizations to restore functionality. Objective: To verify the effects of manual therapy techniques on pain and electromyographic activity (EMG) of masticatory muscles in TMD patients. Methods: This is a quasi-experimental study composed of 10 subjects with TMD and 10 healthy subjects who underwent a session of myofascial release, joint mobilization and digit-pressure on the masticatory and cervical muscles. Pain levels and electromyographic activities of the temporal and masseter muscles were bilaterally assessed during the following situations: (1) Maximum Occlusion and (2) Chewing in the right and the left side with chewing gum. Data analysis was performed using BIOMEC-SAS software, in which the data were filtered with a 4th order Butterworth bandpass filter with $20-400 \mathrm{hz}$ and normalized as a percentage of maximum occlusion. Data were divided into homolateral and contralateral muscles alongside chewing. EMG variables were compared by factorial ANOVA, and pain by dependent t-test. Results: TMD patients had pain level reduction during maximum occlusion (Pre:4.55 \pm 2.2 ; Post:2.55 $\pm 1.6 ; p=<0.001$ ), right chewing (Pre:2.3 $\pm 2.16 ;$ Post:0.4 $\pm 0.69 ; p=0.02$ ) and left chewing (Pre: $1.0 \pm 1.15$; Post:0.10 $\pm 0.31 ; p=0.05$ ). There was no effect of manual therapy techniques on the EMG activity bilaterally of the temporal $(p=0.617)$ and masseter $(p=0.926)$ muscles during chewing. Patients with TMD had higher EMG activities during chewing on the homolateral temporal $(p=0.001)$ and masseter (0.004) muscles compared to subjects without injury. Conclusion: Manual therapy techniques reduced pain level in TMD patients. No changes in EMG activity were observed after manual therapy techniques. Finally, the study provides evidence of the influence of manual therapy techniques on short-term pain.
\end{abstract}

Keywords: Temporomandibular Joint; Electromyography; Masticatory Muscles.

\section{INTRODUCTION}

The temporomandibular joint (TMJ) is a synovial joint composed of the articular eminence of the temporal bone, the mandibular condyle and an intra-articular disc ${ }^{1,2}$. It is one of the most functional joints in the human body encompassing the functions of chewing, swallowing, phonation and mandibular posture, its contribution to the stomatognathic system is notorious ${ }^{3,4}$. Such elucidated functions are dependent on the muscular activity of the medial and lateral pterygoid, temporal and masseter muscles, which promote the mandibular movements of protrusion, retraction, lateral excursion, lowering and elevation ${ }^{5}$. TMJ is susceptible to musculoskeletal and orthopedic disorders, as it involves not only the temporomandibular joint but also the stomatognathic system ${ }^{6}$. The causes of these disorders are not completely elucidated, however it is known that occur neuromuscular, articular, postural and psychological changes. The TMJ disorders are called temporomandibular disorders $(T M D)^{7}$. The origin of the TMD is multifactorial, classified into two categories: intracapsular and extracapsular dysfunctions. Disc displacement occurs in intra-capsular dysfunctions, causing symptoms such as pain, noise, mobility limitation, opening and closing deviations of the mouth, ringing in the ear, dizziness and malocclusion. And muscle spasms and inflammation occur in extracapsular dysfunctions ${ }^{4}$. Amantéa et al. ${ }^{8}$ mentioned that muscle spasm is the main cause of TMD symptoms, and may be triggered by muscle fatigue generated by muscle hyperactivity. Such hyperactivity is triggered by parafunctional habits such as bruxism, emotional stress, anxiety and the adoption of inappropriate postures.

The evaluation of electromyographic activity (EMG) of the TMJ during masticatory function is used to assist in the diagnosis, evaluation and monitoring of TMD treatments ${ }^{6,7,9}$. The literature also uses EMG as a method for comparing healthy subjects with $\mathrm{TMD}^{10-13}$. It is observed anterior temporal muscle hyperactivity ${ }^{7,12}$, temporal ${ }^{7}$, masseter and sternocleideomastoid asymmetry ${ }^{14}$. In addition, muscle fatigue 
and decreased occlusion force are present in patients with $\mathrm{TMD}^{7,15,16}$. Considering the changes in electromyographic activity in patients with TMD, the relevance of the multidisciplinary approach in the treatment of TMD is highlighted ${ }^{2}$. Physical therapy treatment aims to reduce symptomatology, correct and restore TMJ function through electrothermophototherapy resources, kinesiotherapy, and manual therapy techniques. Manual therapy seeks to reestablish function with myofascial releases, joint mobilization, joint manipulation, relaxation and stretching techniques ${ }^{17}$ to promote improvement in range of motion, pain, muscle relaxation and to influence the EMG of muscles involved in TMD patients ${ }^{18-22}$. There is divergence of evidence to support conservative treatment of TMD. Studies that used manual therapy techniques and evaluated EMG did not always adequately specify all procedures that were performed with patients. In addition, these treatments considered only the compensations of the chewing muscles, disregarding the cervical region ${ }^{18,19,23}$. Thus, cervical myofascial release techniques may also contribute to the improvement of symptoms in patients with TMD.

Based on the cited evidence on the complexity of TMJ, TMD and their effects on masticatory muscles, as well as the use of manual therapy in their treatment, this study aimed to verify the effects of the application of manual therapy techniques on pain and electromyography activity of masticatory muscles in patients with temporomandibular disorder.

\section{METHODS}

The study is characterized by being quasi-experimental quantitative, respecting the ethical aspects of Resolution $466 / 12$ or $510 / 16$ of the National Health Council, having been approved by the Research Ethics Committee from Centro Universitário da Serra Gaúcha - FSG, with no 2.797.999. The sample was selected by convenience and composed of 20 subjects separated into intervention group $(n=10)$ and control group $(n=10)$. The subjects of the intervention group (IG) presented a diagnosis of TMD based on the screening evaluation of the Dental Clinic of the Centro Universitário da Serra Gaúcha - FSG and RDC/TDM ${ }^{24}$. Patients who used analgesic drugs or orthodontic appliances at the time of collection, or had previous TMJ fractures or cervical spine dysfunction were excluded from the intervention group. The control group (CG) consisted of healthy subjects with preserved range of motion, no complaints of TMJ pain or discomfort, and were invited to participate in the study through dissemination via social networks. Subjects who presented pain in the TMJ region, who used orthodontic appliances or analgesic drugs for other disorders were excluded from the CG.

All data were collected at the Integrated Health Center of the Centro Universitário da Serra Gaúcha - FSG from September to November 2018 in Caxias do Sul, Rio Grande do Sul, and collections were scheduled and held in one session as participants' availability. The researchers contacted participants linked to the dental clinic via telephone. Consequently, patients who met the criteria and agreed to participate in the study were invited to an assessment day. Initially, the participants signed the Informed Consent Form (ICF) and it was performed a characterization evaluation of patients with temporomandibular disorder (gender, age, pain in the last 4 weeks, professional follow-up, presence of cracks, tired and sore jaw, teeth-grinding habits, tinnitus, migraines and/or headaches). At the end of this research phase, subjects were directed to the collection of electromyographic data. The electromyographic variables were obtained by means of the 4-channel EMG MIOTEC equipped with a 32 bit A/D converter connected to a LeNovo computer. MiotecSuite software with a sampling rate of $2000 \mathrm{~Hz}$ was used. Individually, each participant sat on a chair with a backrest, keeping the head in a neutral position, eyes open, lower limbs resting on the floor, upper limbs resting comfortably on the lower limbs. The patients were positioned in front of the notebook where kinematic chewing data were obtained through the webcam.

Positioned, the subject underwent trichotomy and skin cleansing with $70 \%$ alcohol-soaked cotton in the electrode placement regions, a researcher performed this step using properly sterilized procedure gloves. After skin preparation, the surface electrodes (Ag/AgC1) were placed in the bipolar configuration for the right masseter, left masseter, right temporal, and left temporal muscles ${ }^{13}$. The reference electrode was placed in the right clavicle of the subject. The electrodes were positioned between the motor point and the tendon of the right and left masseter muscles, towards the muscle fibers, and in the anterior portion of the right and left temporal muscle, towards the muscle fibers (Figure 1).

The subjects were instructed to perform the maximal voluntary isometric contraction (MVIC) and for this purpose were used roller type cotton bilaterally between the upper and lower dental arches positioned by the evaluator, wearing sterile gloves. The patient was asked to perform the maximum bite force (maximum occlusion) on the cotton. The MVIC collection consisted of $2 \mathrm{MVIC}$ maintaining contraction for 5 seconds with an interval of 2 minutes between each repetition. At this stage, patients were asked about possible pain or discomfort during maximum occlusion using the visual analogue scale (VAS), which consisted of a graphical and numerical illustration from 0 to 10 that the patient should refer to their pain intensity during the steps. A value of zero (0) represents no pain, while ten (10) represents the highest possible pain. Subsequently, the cotton was removed and chewing gum was delivered. The patients performed chewing movements for 10 seconds on the left side and chewing movements for 10 seconds on the right side. After this gesture, patients were again asked about possible pain or discomfort during chewing. After this step, the evaluator removed the channels, keeping the electrodes positioned on the skin of the subjects, and led the patient to comfortably 


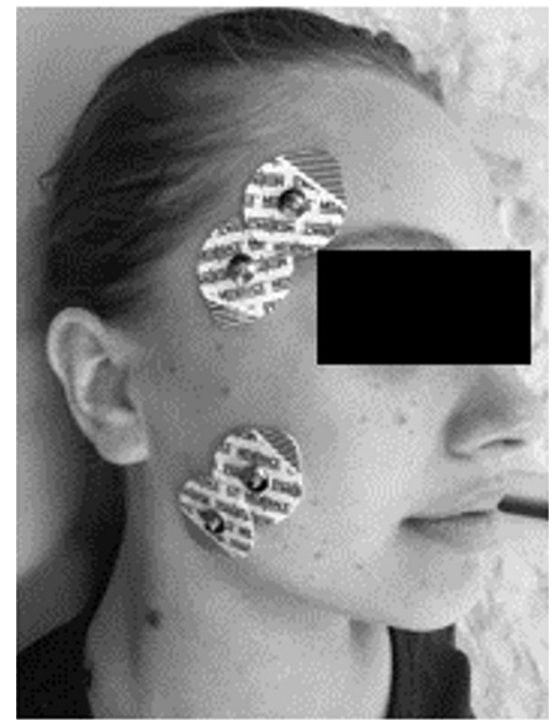

Figure 1. Electrode positioning in the temporal and masseter muscles. lie on a gurney. One evaluator performed manual therapy techniques on the evaluated muscles, the TMJ and cervical muscles (Figure 2 and Figure 3). The manual techniques were performed in the TMJ and the cervical bilaterally and consisted of: (1) digit pressure and slip on trigger points in the right and left masseter muscles (Figure 2-A); (2) intraoral myofascial release of masseter (Figure 2-B) and (3) intraoral joint mobilization, in the craniocaudal and the anteroposterior direction (Figure 2-C). The following manual techniques were also performed: (1) Pompagem and stretches (Figure 3-A); (2) Myofascial release of the upper cervical muscles and joint mobilization in cervical vertebrae (Figure 2-B); (3) digit pressure and slip on trigger points in the right and left temporal muscles (Figure 3-C).

After manual therapy techniques, the 4 electromyographic channels were repositioned and reconnected to the electrodes that remain in the subject. Then, the subject was instructed to perform the maximal bite force again (maximum occlusion)
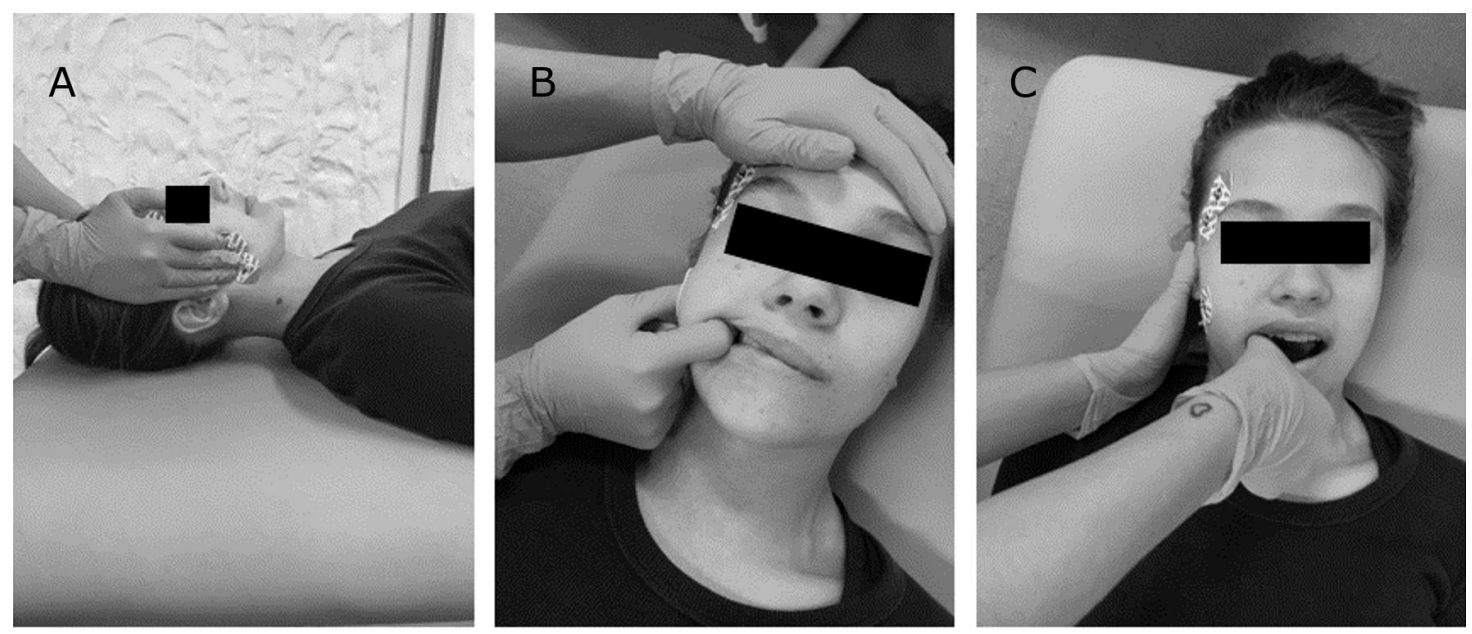

Figure 2. Manual therapy techniques. Note: $A=$ Myofascial release of masseter; $B=$ Intraoral release; $C=$ Joint mobilization.
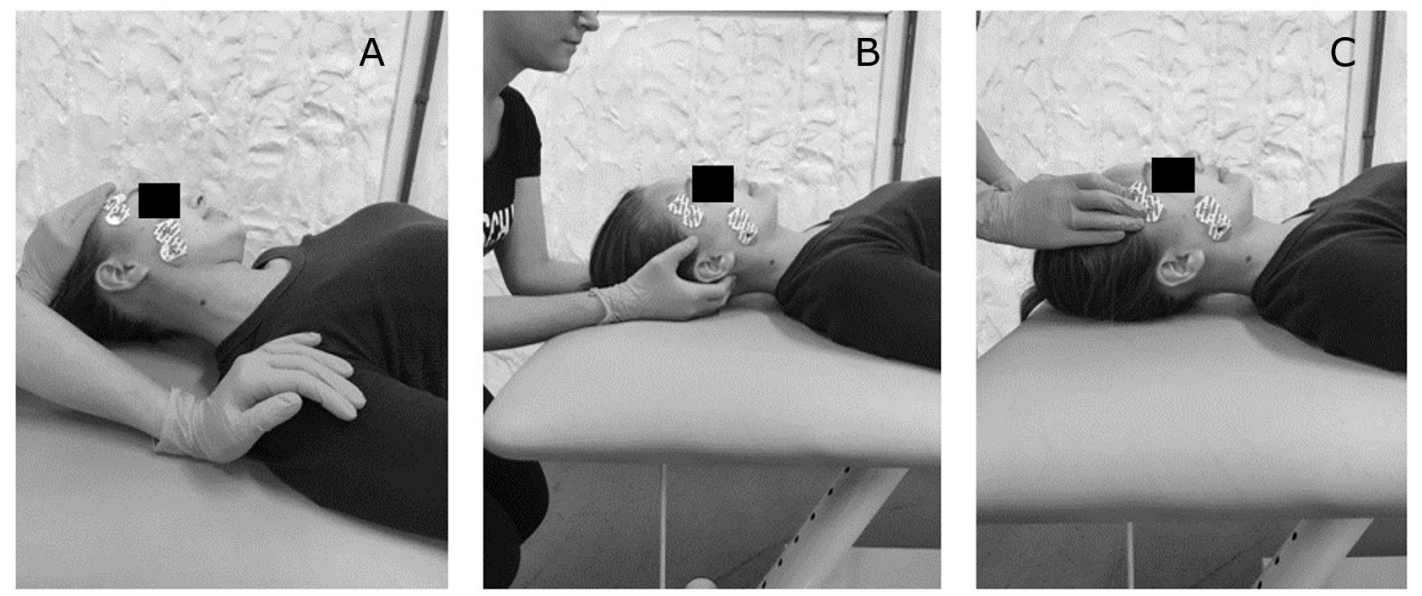

Figure 3. Manual therapy techniques. Note: $A=$ Pompagem and Stretchs; $B=$ Cervical Joint Mobilization; $C=$ Myofascial Release of Temporal. 
on the cottons that were re-delivered and positioned in the same manner as the first maximal bite test. Participants were again asked about possible pain or discomfort during maximum occlusion. Patients were asked to answer honestly if manual therapy techniques reduced pain, they were also instructed that in case of negativity or neutrality this would not alter their contributions to the research and would not be harmed. Cottons were removed and chewing with chewing gum was repeated and asked about possible pain or discomfort during chewing. Finally, the electrodes were disconnected, the skin of the subject was cleaned and their participation in the research was concluded. Electromyographic signals were analyzed using the BIOMEC SAS software ${ }^{25}$. Initially, the signals collected during MVIC and chewing movements were submitted to a digital filtering procedure, using a 4th order Butterworth bandpass filter, with frequency band between 20 and $400 \mathrm{~Hz}$. After the filtering procedure, the central chewing of 10 seconds was validated. This cut was based on cinematic data obtained from the LeNovo computer webcam, which was synchronized with the MiotecSuite software. For MVICs, the peak value of the root-mean-square (RMS) envelope of each muscle collected was used. The electromyographic signal was processed in the time domain from the RMS envelope calculation with 1 second of Hamming window. The RMS value of each muscle studied was normalized by the ratio between the RMS value and the MVIC peak value to obtain the respective chewing data. To minimize discrepancy between the sides of the lesions, chewing on the right and left sides was combined, being defined as chewing of the homolateral (H.L.) and contralateral (C.L.) muscles. The symmetry index was also obtained, which is defined as the ratio between the overlap of two EMG signals of contralateral muscles by the total area of activation of these muscles ${ }^{26}$.

Statistical analysis was performed using the SPSS 20.0 software, which initially verified the normality and homogeneity of the data respectively by the Shapiro-Wilk and Levene tests. The comparisons of the electromyographic data (chewing and symmetry index) were performed by factorial ANOVA, considering the factors 2-level group (TMD Group and Control Group) and 2-level time (Pre and Post Intervention). $F$ ratio (ANOVA), p value (significance level) and effect size $\left(\eta^{2}\right)$ were presented. Regarding pain variables, the dependent t-test (parametric) was used only in the TMD group, as the control group presents a zero index. In case of statistical differences in ANOVA comparisons, the Bonferroni post hoc test was used. The level of significance adopted was $\alpha<0.05$.

\section{RESULTS}

Twenty subjects participated in the study, divided into control group $(n=10)$ and TMD group $(n=10)$, which sample characteristics can be seen in table 1 .
Considering TMD patients: 9 patients (90\%) reported pain in the TMJ region in the last 4 weeks, and $60 \%$ of them did not seek professional help to treat the problem. When asked about crackles in the TMJ region, $90 \%$ of patients reported suffering from the symptom, just as the same number of subjects reported feeling sore and tired jaw, have teeth-grinding habit, tinnitus and headache and/or migraine. Considering the pain variable (Table 2 ) there was a decrease during occlusion $(p=<0.001)$, right chewing $(p=0.02)$ and left chewing $(p=0.05)$ after the application of manual therapy techniques.

Considering the electromyographic activity (Figure 4) it can be observed based on the factorial ANOVA statistical differences between the control group and the TMD group ("group" factor) for the homolateral temporal (H.L.) $\left(F=10.897 ; p=0.001 * ; \eta^{2}=0.125\right)$ and masseter (H.L.) ( $\left.F=9.053 ; p=0.004^{*} ; \eta^{2}=0.106\right)$ muscles during chewing. The contralateral muscles (C.L.) to chewing, temporal $\left(F=0.377 ; p=0.541 ; \eta^{2}=0.05\right)$ and masseter $(F=2.405$; $p=0.125 ; \eta^{2}=0.11$ ) did not obtained difference. Considering the symmetry index, there was no difference between the pre and post intervention values of the temporal muscles (Pre - $74.78 \pm 18.23 \%$; Post $-78.6 \pm 17.9 \%$; $p=0.4$ ) and masseter (Pre = $81.96 \pm 10.4$; Post $=83.62 \pm 14.9 ; p=0.91$ ).

Considering the "group * time" factor (Figure 4) during chewing pre and post manual therapy techniques in subjects with TMD, no statistical differences were found for temporal H.L. $\left(F=0.252 ; p=0.617 ; \eta^{2}=0.03\right)$, masseter H.L. $\left(F=0.009 p=0.926 ; \eta^{2}=0.01\right)$, temporal C.L. $\left(F=0.397 ; p=0.530 ; \eta^{2}=0.05\right)$ and masseter C.L. $(F=0.848$; $p=0.360 ; \eta^{2}=0.11$ ) muscles.

Table 1. Characterization of the sample

\begin{tabular}{ccc}
\hline Variable & $\begin{array}{c}\text { Control Group } \\
(\mathbf{n}=\mathbf{1 0})\end{array}$ & $\begin{array}{c}\text { TMD Group } \\
(\mathbf{n}=\mathbf{1 0})\end{array}$ \\
\hline FEMALE & $8-80 \%$ & $8-80 \%$ \\
MALE & $2-20 \%$ & $2-20 \%$ \\
AGE & $25.5 \pm 4.3$ years & $45.4 \pm 12.2$ years \\
WEIGHT & $68.5 \pm 12.2 \mathrm{~kg}$ & $72.3 \pm 9.1 \mathrm{~kg}$ \\
HEIGHT & $163 \pm 6.4 \mathrm{~cm}$ & $156 \pm 7.3 \mathrm{~cm}$ \\
PAIN (REP.) & 0 & $2.6 \pm 1.8$ \\
\hline
\end{tabular}

Table 2. Pain levels pre and post manual therapy techniques.

\begin{tabular}{cccc}
\hline & Pre & Post & p \\
\hline Maximum Occlusion & $4.55 \pm 2.20$ & $2.55 \pm 1.60$ & $<0.001^{*}$ \\
R Chewing & $2.30 \pm 2.16$ & $0.40 \pm 0.69$ & $0.02^{*}$ \\
L Chewing & $1.00 \pm 1.15$ & $0.10 \pm 0.31$ & $0.05^{*}$ \\
\hline
\end{tabular}




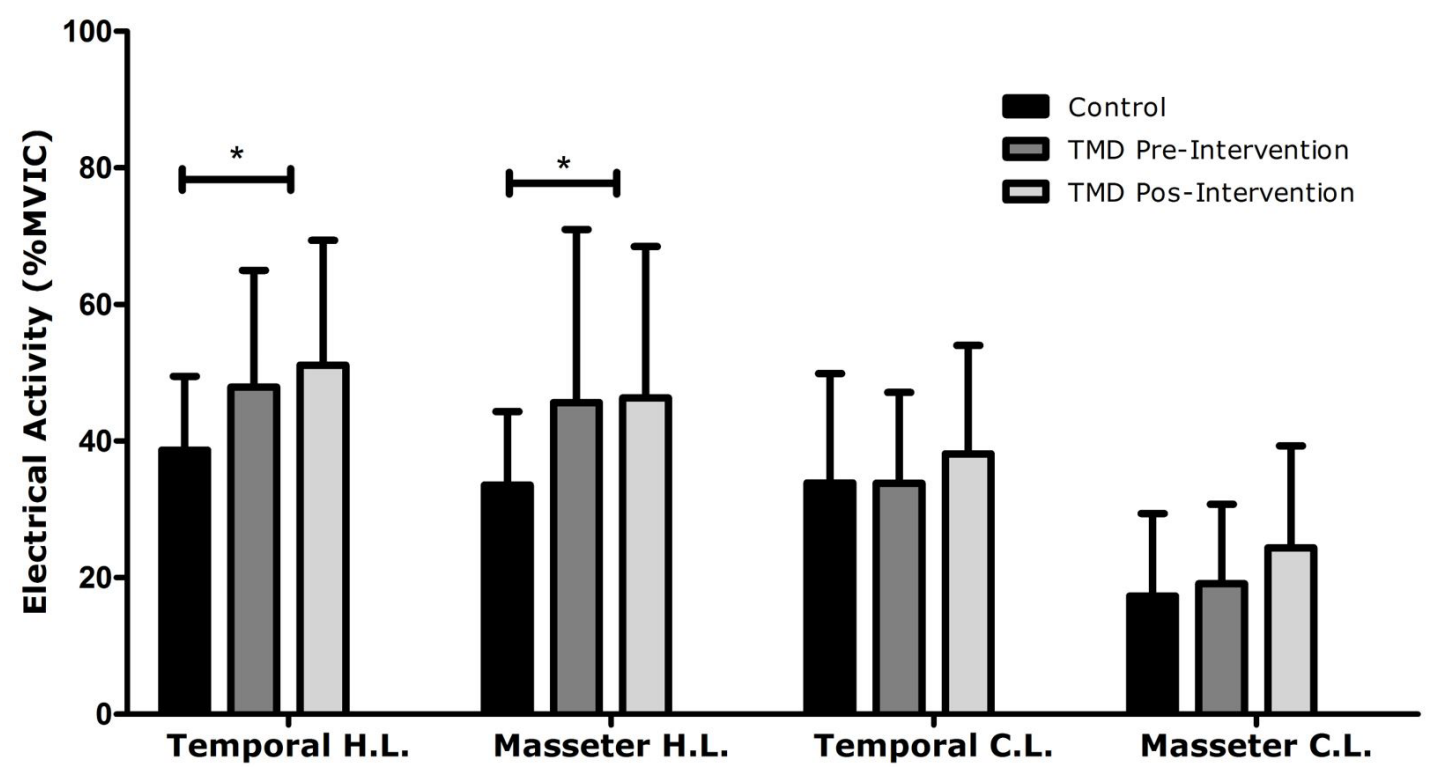

Figure 4. Electromyographic activity as a percentage of maximal voluntary isometric contraction during chewing.

\section{DISCUSSION}

It can be verified that the pain level decreased during maximum occlusion, chewing and rest after manual therapy techniques. Regarding the electromyographic activity, it can be observed a difference between the CG and the IG for the homolateral temporal and masseter muscles during chewing. Pain reduction has occurred in several literature studies during Trigger Point inhibition ${ }^{27}$, myofascial release with slip and compression ${ }^{18}$, joint mobilization ${ }^{28}$, intraoral release ${ }^{29}$ techniques, similar to the techniques used in the present study. There are indications that manual therapy is one of the most effective physical therapy resources for reducing pain levels in $\mathrm{TMD}^{21,30}$, corroborating our results, in which it was found that the level of pain reduced in maximum occlusion, chewing and rest movements after manual therapy techniques in IG. Among the manual therapy techniques that can lead to pain reduction, myofascial release reduces soft tissue tension and adhesions and eliminates trigger points mainly in the masseter muscles, as it acts on the sensory system through the Golgi tendon organ, acting on tissue properties stimulating the elasticity of adhered fibers. Passive joint mobilization stimulates synovial fluid production in the TMJ, causing a sensation of relaxation and allowing greater range of motion. Passive movement is able to provide central and cortical stimuli, precisely because it acts at the level of proprioceptive receptors, which respond to changes in muscle tension, tendon and capsular-ligament elements and subsequently decrease pain levels $\mathrm{s}^{20-22}$.

Muscle pain is the main and most frequent symptom reported by patients with temporomandibular disorders ${ }^{21}$ with a predominantly female prevalence ${ }^{22}$, similar to the data observed in this study, which $20 \%$ of the sample subjects were males. Regarding age, the average age of patients with TMD is between twenty and fifty years old ${ }^{22}$ also consistent with our study. Since pain is the most common symptom, it is associated with muscle tension, and may range from mild discomfort to extreme discomfort, especially in the face, jaw, temples and neck $^{21}$ that can also cause ROM loss ${ }^{31}$. Similar to the findings, it was observed that the patients presented pain in facial regions. Symptoms such as crackling, tinnitus, teeth-grinding habit, discomfort during occlusion cause increased level of pain in the TMJ region ${ }^{1,2,21}$.

The reduced sensitivity of mechanoceptors explains the analgesia caused by manual treatments, since these techniques reduce pain, as they interfere with tissue properties and may influence muscle function, which can be visualized through $\mathrm{EMG}^{17-19,21,22,30,32-34}$.

Gonzalez and Bérzin ${ }^{18}$ developed a similar study, in which they evaluated pain and EMG of the masseter and temporal muscles bilaterally in TMD patients after the application of manual therapy techniques. The results of the study indicated that EMG decreased, not resembling the findings of this study. In contrast, the patients' pain level decreased, as it did in this study. Bortolazzo et $a l .^{35}$, after manipulation of the upper cervical, which was not used in the present study, found a decrease in EMG of right temporal and left masseter during rest and mouth opening. Although the present study demonstrates benefits regarding the reduction of pain level in the IG, there was no effect of manual therapy on the electromyographic activity of the evaluated masticatory muscles, not confirming with the results of studies in which manual therapy reduced 
electrical activity in TMD patients ${ }^{18,35}$, however, the analyzes were performed during rest and mouth opening ${ }^{35}$ and with non-normalized signs of EMG ${ }^{18}$. Evidences are also found that agrees with the present study, in which the digit-pressure technique on the masseter reduced pain symptoms but did not alter EMG during maximum occlusion ${ }^{19}$. It is speculated that one of the factors for TMD correction and EMG signal alteration may be linked to long-term treatments, since with the reduction of pain the tendency is to decrease the muscle recruitment capacity during movement of maximum occlusion and chewing, restoring "normal" muscle functions. However, it is also argued that patients with severe TMD show only improvement in pain level in one or a few treatment sessions, and maintain para-functional habits ${ }^{36}$ possibly not altering their electromyographic signals. These data may explain our results regarding the fact that the electromyographic activity was not significant after only a short-term session of the manual therapy technique. Regarding the comparison during chewing between patients with TMD and control group, the results of the present study agree with the literature findings that present hyperactivity of the anterior temporal muscle ${ }^{7,12}$. It is noted that the temporal also presents a greater asymmetry when compared to healthy subjects ${ }^{7}$, as well as the masseter and sternocleideomastoid muscles ${ }^{14}$. It is also noteworthy that commonly during chewing, patients may use the contralateral side of the lesion, which results in greater EMG of the temporal and masseter ${ }^{13}$, however in our study there is an mean increase, but not significant in these variables.

The study has limitations that should be mentioned. The small proportion sample, from the methodological point of view, may have been one of the reasons why there is no influence of manual therapy techniques on EMG. Considering also a single application of the manual intervention, nor which specific technique acts in long term treatment, so it is therefore relevant that further studies should be conducted considering the long term results. In addition, there were limitations considering the fact that the manual technique and the range of motion assessment was not applied in the CG, not allowing evidence of the behaviors of these variables after short-term intervention in these populations.

\section{CONCLUSION}

Manual therapy techniques reduced pain level during maximal occlusion, chewing and rest in patients with temporomandibular disorder. There was no statistical difference in the electromyographic activity of the temporal and masseter muscles during chewing. Thus, although there was no change in electromyographic activity, there was a significant improvement in pain in patients with TMD. Consequently, it has contributed notably to the short-term rehabilitation process, as pain is the main complaint of patients with TMD. To investigate the influences on electromyographic activity, further long-term studies should be conducted with this same population.

\section{AUTHORS' CONTRIBUTIONS}

PBB: responsible for the study development, data collection, data analysis, discussion and article writing; MAB: responsible for the development of the study and discussion; WD: project Coordinator, responsible for the development, collection, data analysis and discussion of the article.

\section{CONFLICTS OF INTEREST}

nothing to declare.

\section{REFERENCES}

1. Pelicioli M, Myra RS, Florianovicz VC, Batista JS. Physiotherapy treatment in temporomandibular disorders. Revista Dor. 2017;18(4):355-61.

2. Torres F, Campos LG, Fillipini HF, Weigert KL, Dalla Vecchia GF. Efeitos dos tratamentos fisioterapêutico e odontológico em pacientes com disfunção temporomandibular. Fisioterapia em Movimento. 2017;25(1): 117-125.

3. Menezes MS, Bussadori SK, Fernandes KPS, Biasotto-Gonzalez DA. Correlação entre cefaléia e disfunção temporomandibular. Fisioterapia e Pesquisa. 2008;15(2):183-7.

4. Di Grazia RC. As alterações posturais relacionadas com a disfunção da articulação temporomandibular e seu tratamento. 2003.

5. Neumann DA. Cinesiologia do aparelho musculoesquelético: fundamentos para reabilitação: Elsevier Health Sciences; 2010.

6. Costa, LMRD. Efeito do método pilates nas desordens temporomandibulares em mulheres: um ensaio clínico randomizado. Universidade Federal do Rio Grande do Sul- Porto Alegre, Brasil-2017.

7. Tartaglia GM, Lodetti G, Paiva G, De Felicio CM, Sforza C. Surface electromyographic assessment of patients with long lasting temporomandibular joint disorder pain. Journal of Electromyography and Kinesiology. 2011;21(4):659-64.

8. Amantéa DV, Novaes AP, Campolongo GD, Barros TPd. The importance of the postural evaluation in patients with temporomandibular joint dysfunction. Acta Ortopédica Brasileira. 2004;12(3):155-9.

9. Malta J, Campolongo GD, de Barros TEP, de Oliveira RP. Eletromiografia aplicada aos músculos da mastigação. Acta Ortopédica Brasileira. 2006;14(2):106-7.

10. Pires PF, Rodrigues-Bigaton D. Evaluation of integral electromyographic values and median power frequency values in women with myogenous temporomandibular disorder and asymptomatic controls. Journal of bodywork and movement therapies. 2018;22(3):720-6.

11. Ferreira CLP, Machado BCZ, Borges CGP, Da Silva MAMR, Sforza C, De Felício CM. Impaired orofacial motor functions on chronic temporomandibular disorders. Journal of Electromyography and Kinesiology. 2014;24(4):565-71.

12. Pitta NC, Nitsch GS, Machado MB, de Oliveira AS. Activation time analysis and electromyographic fatigue in patients with temporomandibular disorders during clenching. Journal of Electromyography and Kinesiology. 2015;25(4):653-7.

13. Santana-Mora U, Cudeiro J, Mora-Bermúdez M, Rilo-Pousa B, FerreiraPinho J, Otero-Cepeda J, et al. Changes in EMG activity during clenching in chronic pain patients with unilateral temporomandibular disorders. Journal of Electromyography and Kinesiology. 2009;19(6):e543-e9.

14. Gerdi KRL, Correa AM, Berzin F. Asymmetric activation of temporalis, masseter, and sternocleidomastoid muscles in temporomandibular disorder patients. CRANIO. 2008;26(1):59-64.

15. Ferrato G, Falisi G, lerardo G, Polimeni A, Di Paolo C. Digital evaluation of occlusal forces: comparison between healthy subjects and TMD patients. Annali di stomatologia. 2017;8(2):79.

16. Politti F, Casellato C, Kalytczak MM, Garcia MBS, Biasotto-Gonzalez DA. Characteristics of EMG frequency bands in temporomandibullar disorders patients. Journal of Electromyography and Kinesiology. 2016;31:119-25. 
17. Cuccia A, Caradonna C, Annunziata V, Caradonna D. Osteopathic manual therapy versus conventional conservative therapy in the treatment of temporomandibular disorders: a randomized controlled trial. Journal of bodywork and movement therapies. 2010;14(2):179-84.

18. Biasotto-Gonzalez DA, Bérzin F. Electromyographic study of patients with masticatory muscles disorders, physiotherapy treatment (massage). Brazilian Journal of Oral Sciences. 2016;3(10):516-21.

19. de Paula Gomes CAF, El Hage Y, Amaral AP, Politti F, Biasotto-Gonzalez DA. Effects of massage therapy and occlusal splint therapy on electromyographic activity and the intensity of signs and symptoms in individuals with temporomandibular disorder and sleep bruxism: a randomized clinical trial. Chiropractic \& manual therapies. 2014;22(1):43.

20. Fernandes WVB, Michelotto AB, Kimura S. Comparação entre Técnicas Osteopáticas e Fisioterapia Convencional para o Tratamento das Desordens Temporomandibulares. A REVISTA. 2009:29.

21. Paiva ACBO, de Sousa RA. Efeito da terapia manual em pacientes com disfunção crâniomandibular: revisão bibliográfica. AMAZÔNIA: SCIENCE \& HEALTH. 2015;3(1):33-6.

22. Santos LdFdS, Pereira MCA. A efetividade da terapia manual no tratamento de disfunções temporomandibulares (DTM): uma revisão da literatura. Revista de Atenção à Saúde (antiga Rev Bras Ciên Saúde). 2016;14(49):72-7.

23. Butts R, Dunning J, Pavkovich R, Mettille J, Mourad F. Conservative management of temporomandibular dysfunction: A literature review with implications for clinical practice guidelines (Narrative review part 2). Journal of bodywork and movement therapies. 2017;21(3):541-8.

24. Lucena LBSd, Kosminsky M, Costa LJd, Góes PSAd. Validation of the Portuguese version of the RDC/TMD Axis II questionnaire. Brazilian oral research. 2006;20(4):312-7.

25. Torre ML. Desenvolvimento de um software para processamento e análise de sinais biológicos utilizados em biomecânica [Tese].Porto Alegre: Universidade Federal do Rio Grande do Sul. 2013.

26. Ferrario V, Sforza C, Colombo A, Ciusa V. An electromyographic investigation of masticatory muscles symmetry in normo-occlusion subjects. Journal of oral rehabilitation. 2000;27(1):33-40.

27. Sousa C. O efeito da técnica de inibição de Jones nos músculos Masseter e temporal nas disfunções temporomandibulares: Instituto Politécnico do Porto. Escola Superior de Tecnologia da Saúde do Porto; 2013.
28. Lopes FdOT. Efeito da mobilização articular da ATM na dor, no sinal eletromiográfico e na amplitude de movimento de mulheres com DTM muscular. 2012.

29. Kalamir A, Pollard H, Vitiello A, Bonello R. Intra-oral myofascial therapy for chronic myogenous temporomandibular disorders: a randomized, controlled pilot study. Journal of Manual \& Manipulative Therapy. 2010;18(3):139-46.

30. Tuncer $A B$, Ergun $N$, Tuncer $A H$, Karahan S. Effectiveness of manual therapy and home physical therapy in patients with temporomandibular disorders: A randomized controlled trial. Journal of bodywork and movement therapies. 2013;17(3):302-8.

31. Guimarães, É. A., Makhoul, K. D. L., de Matos Boaventura, C., Ferreira, A. L., Sousa, L. R., da Silva, R. M., \& Lima, K. R. (2018). Temporomandibular dysfunction and functional mandibular limitation. Manual Therapy, Posturology \& Rehabilitation Journal, 2018;16:0-0.

32. Martins WR, Blasczyk JC, de Oliveira MAF, Gonçalves KFL, Bonini-Rocha AC, Dugailly P-M, et al. Efficacy of musculoskeletal manual approach in the treatment of temporomandibular joint disorder: A systematic review with meta-analysis. Manual Therapy. 2016;21:10-7.

33. von Piekartz H, Hall T. Orofacial manual therapy improves cervical movement impairment associated with headache and features of temporomandibular dysfunction: A randomized controlled trial. Manual Therapy. 2013;18(4):345-50.

34. Capellini VK, Souza GSd, Faria CRSd. Massage therapy in the management of myogenic TMD: a pilot study. Journal of Applied Oral Science. 2006;14(1):21-6.

35. Bortolazzo GL, Pires PF, Dibai-Filho AV, Berni KCdS, Rodrigues BM, Rodrigues-Bigaton D. Efeitos da manipulação cervical alta sobre a atividade eletromiográfica dos músculos mastigatórios e amplitude de movimento de abertura da boca em mulheres com disfunção temporomandibular: ensaio clínico randomizado e cego. Fisioterapia e Pesquisa. 2015;22(4):426-34.

36. Turcio KH, Garcia AR, Derogis AR, Zuim PR. Avaliação eletromiográfica e eletrovibratográfica antes e após o tratamento da desordem temporomandibular. Brazilian Dental Science. 2010;5(2). 